\title{
Long-Term Effects of Iron Chelating Agents on Ocular Function in Patients with Thalassemia Major
}

\author{
Raffaele Nuzzi iD ' \\ Giada Geronazzo ${ }^{1,2}$ \\ Federico Tridico (iD) \\ Alessia Nuzzi ${ }^{3}$ \\ Paolo Caselgrandi (D) \\ Antonio Giulio Piga (iD ${ }^{4}$ \\ 'Eye Clinic Section, Department of \\ Surgical Sciences, University of Turin, \\ Turin, Italy; ${ }^{2}$ Regional Reference Centre \\ for Diagnosis and Cure of \\ Hemoglobinopathies, S. Luigi Gonzaga \\ University Hospital, University of Turin, \\ Orbassano (TO), Italy; ${ }^{3}$ Department of \\ Clinical Sciences and Community Health, \\ Eye Clinic San Giuseppe Hospital, IRCCS \\ Multimedica, University of Milan, Milan, \\ Italy; ${ }^{4} \mathrm{Head}$ of Regional Reference \\ Centre for Diagnosis and Cure of \\ Hemoglobinopathies, S. Luigi Gonzaga \\ University Hospital, University of Turin, \\ Orbassano (TO), Italy
}

Background: The aim of this study is to evaluate eye structures and function in patients receiving iron chelating therapy and to assess whether a correlation exists between the onset of ocular alterations and the intake of iron chelating drugs.

Methods: A prospective cohort study was performed. Eighty-eight patients, composed of children and adults with thalassemia major (TM) who are taking or had taken iron chelating drugs (deferoxamine, deferiprone or deferasirox), have been initially enrolled in the study. The final sample featured 80 patients, including 18 children and 62 adults. These subjects received an eye examination to evaluate intraocular pressure (IOP), best corrected visual acuity (BCVA), the presence of refractive defects, cornea, anterior chamber, lens, fundus oculi, visual field and mean retinal nerve fiber layer (RNFL) thickness. Logistic regression model analysis was performed in order to assess any correlation. In addition, a literature search regarding the relation between iron chelating drugs and ocular adverse events was carried out to compare the results obtained with the evidence in the literature.

Results: Logistic regression did not report a significant correlation between the intake of iron chelating drugs and the onset of anterior ocular segment alterations, lens opacities, retinal diseases, optical neuropathies, astigmatism, visual field and RNFL thickness defects. Logistic regression returned a statistically significant correlation between myopia and iron chelation therapy (p-value 0.04; OR 1.05) and also between presbyopia and total duration of therapy with deferoxamine (p-value 0.03; OR 1.21). Although intraocular pressure levels remained within the normal range, a significant correlation with the length of deferoxamine therapy has been found ( $p$-value 0.002 ; association coefficient -0.12 ). A negative correlation between deferiprone and presbyopia has also been observed.

Conclusion: Iron chelation therapy is not associated with severe visual function alterations. Limitation of deferoxamine treatment can help prevent ocular complications. Deferiprone and/or deferasirox may be preferable, especially in patients over age 40 years.

Keywords: iron chelation, ocular adverse effects, deferiprone, deferasirox, deferoxamine

\section{Background}

Thalassemia major (TM), a blood disorder inherited in an autosomal recessive manner, is caused by mutation of the $\beta$ globin chain gene ${ }^{1,2}$ which leads to a severe anemic state. ${ }^{3}$ Conservative therapy with regular red blood cell (RBC) transfusion $^{4-7}$ is effective in replacing missing hemoglobin but results in progressive iron overload with long-term toxicity. ${ }^{8}$ For this reason, this treatment is combined with daily intake of iron chelating agents ${ }^{9-12}$ (deferoxamine, ${ }^{4}$ deferiprone $^{13}$ or deferasirox). ${ }^{13-15}$
Correspondence: Raffaele Nuzzi Eye Clinic Section, Department of Surgical Sciences, University of Turin, Via Cherasco 23, Turin, 10126, Italy Email prof.nuzzi_raffaele@hotmail.it 
While iron chelating drugs are essential for overall survival and complication-free survival, they carry considerable side effects. ${ }^{13,16,17}$ Among the less studied ones are ophthalmic complications: various case reports ${ }^{18-28}$ described a relationship between initiation of chelation therapy and onset of ocular symptoms. However, no systematic reviews published to date indicated whether these events are frequently related to specific risk factors or preventable. Furthermore, it has not yet been established whether ophthalmological complications may be related to the dosage of chelating agents or their intake time. The majority of articles refer to deferoxamine, ${ }^{16,20-41}$ while data about deferiprone ${ }^{18,19,32}$ and deferasirox ${ }^{42,43}$ are poor and do not allow to draw any conclusions.

The aim of this observational study is to evaluate the eye structures and function in patients receiving iron chelating therapy and to determine whether a correlation exists between the onset of ocular alterations related to iron overload and the intake time and/or dosage of iron chelating drugs. In addition, we searched medical databases to assess whether the prevalence of such alterations in patients treated with iron chelating agents is higher than healthy population.

\section{Methods}

This prospective cohort study was approved by our institutional ethics committee (San Luigi Gonzaga Ethics Committee). Written consent to participate was collected by all participants upon registration. All procedures in this study concerning his conduction and documentation were performed in conformity with the ethical principles set out in the Helsinki Declaration and its revisions. All participants were informed about the purpose of the study; a parent or legal guardian of the children provided informed consent.

\section{Patients}

The study population was composed of children and adults with Thalassemia Major (TM), who were taking or had taken iron chelating drugs. These patients were followed at our institution, San Luigi Gonzaga University Hospital (Orbassano, Turin), the Regional Reference Center for Hemoglobinopathies in Piedmont and Valle d'Aosta. Inclusion criteria were as follows: diagnosis of TM and in regular follow-up; regular transfusion therapy and chelation therapy with deferoxamine, deferiprone and/or deferasirox; good compliance with chelation therapy, with respect by the patient of the intake times and doses of chelating drugs indicated by the medical staff. Exclusion criteria were as follows: diabetic retinopathy, glaucoma and any form of ocular alteration pre-existing the start of iron chelation therapy.

Initially, 88 patients were enrolled in the study. Data were collected via direct interview and with the help of the Digital Clinical Folder Management Software WebTHAL. ${ }^{44}$ Collected data included demographic (gender, age, ethnicity) and medical history regarding the disease (date of diagnosis), its complications and treatment (first transfusion date, initiation of chelation therapy, intake times and doses of chelating agents, splenectomy and transplant dates).

Eight of the 88 patients initially enrolled in the study were excluded: 2 adults who did not report diabetic retinopathy and 6 children under the age of 5 years who did not collaborate during the eye examination. The final sample featured 80 patients (160 eyes), including 18 children ( 8 girls and 10 boys; mean age $10.6 \pm 4$ years) and 62 adults ( 40 women and 22 men; mean age $38.4 \pm 7.2$ years) (Table 1 ).

\section{Eye Examination}

All patients received eye examinations to evaluate intraocular pressure (IOP), best-corrected visual acuity (BCVA), refractive defects (including the presence of presbyopia), cornea, anterior chamber, lens, and fundus oculi.

IOP was measured with a Topcon CT-80 air jet tonometer for noninvasive examination and screening. BCVA, refractive defects and presbyopia were measured and evaluated first using a Shin Nippon automatic refractometer and then Snellen eye charts with letters or Albini's "E". Cornea, anterior chamber and lens were observed using a Haag Streit 900 slit lamp. Fundus oculi examination was performed at the slit lamp with the use of additional Volk lenses after mydriasis induction with phenylephrine $1 \%+$ tropicamide $0.5 \%$ eye drops in adults, or tropicamide $1 \%$ in children. Then, all subjects received an evaluation of both visual field and mean peripapillary retinal nerve fiber layer (RNFL) thickness. Both manual (Goldmann perimeter, Haag-Streit, Bern, Switzerland) and automated methods (Humphrey Field Analyzer, Carl Zeiss Meditec, Berlin, Germany) were applied to visual field examination. The mean peripapillary RNFL thickness assessments were performed through ocular Spectral-Domain Optical Coherence Tomography (Spectralis HRA + OCT; Heidelberg Engineering, Heidelberg, Germany).

Normal values were defined according to standard parameters (Table 2). 
Table I Features of Population in Study

\begin{tabular}{|c|c|c|c|}
\hline & Children & Adults & Total \\
\hline SEX & $8 F+10 M$ & $40 F+22 M$ & $48 F+32 M$ \\
\hline AGE (years) & $\begin{array}{l}10.6 \pm 4.0(4.2-17.2) \\
9.0-10.2-12.8\end{array}$ & $\begin{array}{l}38.4 \pm 7.2(18.5-50.0) \\
36.3-39.9-42.5\end{array}$ & $\begin{array}{l}32.2 \pm 13.4(4.2-50.0) \\
20.8-38.8-41.4\end{array}$ \\
\hline TRANSFUSIONS (years) & $\begin{array}{l}9.1 \pm 3.2(4.0-14.2) \\
7.8-9.0-11.3\end{array}$ & $\begin{array}{l}37.3 \pm 7.7(18.1-49.4) \\
34.2-39.2-42.0\end{array}$ & $\begin{array}{l}30.9 \pm 13.7(4.0-49.4) \\
19.3-38.0-40.6\end{array}$ \\
\hline SPLENECTOMY (\%) & $0 \%$ & $71 \%$ & $55 \%$ \\
\hline TRANSPLANTATION (\%) & $11 \%$ & $0 \%$ & $2.5 \%$ \\
\hline COMPLICATIONS (\%) & $33.3 \%$ & $100 \%$ & $85 \%$ \\
\hline TOTAL CHELATING TIME (years) & $\begin{array}{l}7.9 \pm 2.9(2.8-11.5) \\
6.6-8.3-10.3\end{array}$ & $\begin{array}{l}32.8 \pm 7.8(14.0-45.8) \\
29.0-35.2-36.7\end{array}$ & $\begin{array}{l}27.2 \pm 12.6(2.8-45.8) \\
|7.7-3| . \mid-35.9\end{array}$ \\
\hline DEFEROXAMINE TIME (years) & $\begin{array}{l}3.9 \pm 1.4(2.5-6.3) \\
2.8-3.3-5.0\end{array}$ & $\begin{array}{l}20.3 \pm 8.0(7.0-36.8) \\
13.8-21.6-26.0\end{array}$ & $\begin{array}{l}16.6 \pm 9.9(2.5-36.8) \\
7.5-15.0-23.9\end{array}$ \\
\hline DEFEROXAMINE DOSE (mg/Kg/die) & $\begin{array}{l}32.9 \pm 2.6(29.0-38.0) \\
33.0-33.0-34.0\end{array}$ & $\begin{array}{l}36.1 \pm 7.5(15.0-53.0) \\
31.0-38.0-39.75\end{array}$ & $\begin{array}{l}35.4 \pm 6.8(15.0-53.0) \\
31.0-36.5-39.0\end{array}$ \\
\hline DEFERIPRONE TIME (years) & 0 & $\begin{array}{l}6.5 \pm 7.2(0.0-21.1) \\
0.8-3.0-12.8\end{array}$ & $\begin{array}{l}5.0 \pm 6.9(0.0-21.1) \\
0.0-1.4-6.6\end{array}$ \\
\hline DEFERIPRONE DOSE $(\mathrm{mg} / \mathrm{Kg} / \mathrm{die})$ & 0 & $\begin{array}{l}73.7 \pm 37.7(0.0-118.0) \\
51.5-91.0-102.0\end{array}$ & $\begin{array}{l}57.2 \pm 45.3(0.0-118.0) \\
0.0-73.5-101.3\end{array}$ \\
\hline DEFERASIROX TIME (years) & $\begin{array}{l}4.0 \pm 2.3(0.0-7.0) \\
3.3-4.5-5.2\end{array}$ & $\begin{array}{l}6.0 \pm 4.3(0.0-14.1) \\
2.0-6.1-8.1\end{array}$ & $\begin{array}{l}5.6 \pm 4.0(0.0-14.1) \\
2.0-5.9-7.6\end{array}$ \\
\hline DEFERASIROX DOSE (mg/Kg/die) & $\begin{array}{l}25.8 \pm 10.0(0.0-35.0) \\
25.0-28.0-31.0\end{array}$ & $\begin{array}{l}25.2 \pm 10.1(0.0-44.0) \\
21.0-29.0-31.0\end{array}$ & $\begin{array}{l}25.4 \pm 10.0(0.0-44.0) \\
21.0-28.5-31.0\end{array}$ \\
\hline
\end{tabular}

Table 2 Estimated Parameters

\begin{tabular}{|c|c|c|}
\hline & $\begin{array}{l}\text { Method of } \\
\text { Execution }\end{array}$ & Normality \\
\hline $\begin{array}{l}\text { Cornea and } \\
\text { anterior chamber }\end{array}$ & Slit lamp & $\begin{array}{l}\text { No abnormalities or } \\
\text { minor physiological } \\
\text { alterations }\end{array}$ \\
\hline Lens & Slit lamp & No opacity \\
\hline $\begin{array}{l}\text { Posterior chamber } \\
\text { and fundus oculi }\end{array}$ & $\begin{array}{l}\text { Slit lamp with } \\
\text { additional lenses, } \\
\text { in midriasis }\end{array}$ & $\begin{array}{l}\text { Papilla, vases and retina } \\
\text { morphology within } \\
\text { physiological limits }\end{array}$ \\
\hline $\begin{array}{l}\text { Visual acuity/ } \\
\text { Refractive errors } \\
\text { and presbyopia }\end{array}$ & Eye charts & $10 / 10$ without lens need \\
\hline IOP & Air jet tonometer & $</=21 \mathrm{mmHg}$ \\
\hline Visual field & $\begin{array}{l}\text { Manual and } \\
\text { computerized }\end{array}$ & No shrinkage or stricture \\
\hline RNFL thickness & $\begin{array}{l}\text { Spectral-domain } \\
\text { OCT }\end{array}$ & $98.1 \pm 10.9 \mu \mathrm{m}$ \\
\hline
\end{tabular}

\section{Statistical Analysis}

To determine whether a statistically significant correlation exists between ophthalmological alterations and intake time/maximum intake dose of chelating drugs, we used logistic regression models with monoparametric analysis that included variables of primary interest. The variables related to chelating agents' intake were re-evaluated with multiparametric tests that accounted also for age, sex, duration of transfusion therapy and adverse events.

All analyses were performed with SPSS 20.0 statistical software.

\section{Literature Search}

Literature search was performed on PubMed and Cochrane Library databases with the string: ((c(c(()("Iron Chelating Agents"[Mesh]) OR "Iron Chelator*”) OR "Iron Chelation*”) OR "Iron Chelate*”)) OR ((((((exjade) OR deferasirox) OR deferoxamine) OR desferal) OR deferiprone) OR Ferriprox $)))$ AND (((()(((“Eye Diseases”[Mesh] 
OR “eye disease*”)) OR “ocular disease*”) OR "retinal diseases") OR “crystalline lens”[Title/Abstract]) OR “visual field"[Title/Abstract]) OR "intraocular pressure"[Title/ Abstract]) OR ophthalmic[Title/Abstract]))) AND ((“Thalassemia”[Mesh]) OR "beta-Thalassemia"[Mesh] OR "beta Thalassemia" OR "thalassemia major" OR "beta Type Microcytemia" OR "Mediterranean Anemia" OR "Hemoglobin F Disease” OR drepanocytosis OR “Cooley's Anemia” OR “Cooley Anemia”).

In addition, we searched the same platforms for epidemiological data of ocular alterations within the general population.

The last search was done on November 30, 2020.

With our search string, we found 42 articles; an additional one was found after removing the last section from the string (concerning TM). Only 24 of these articles were included as they were relevant to the subject and considered the evaluated parameters. Four articles were important to the topic but did not focus on evaluated parameters; five were unavailable as full text because outdated; residual articles were excluded because irrelevant to the subject or published in a foreign language (Figure 1).

\section{Results}

The duration of transfusion therapy in children ranged from 4.0 to 17.2 years. None of them underwent splenectomy; one patient was waiting for transplantation. Despite their young age, six patients had already developed complications related to the underlying disease (cholelithiasis, kidney stones, osteoporosis). The overall duration of chelation therapy depended on the patients' age (median 8.3 years, first and third quartiles 6.6 and 10.3 years, respectively). None of the patients received deferiprone; the drug used the longest was deferasirox, at a maximum dose of $25.8 \pm 10 \mathrm{mg} / \mathrm{kg} /$ day.

The duration of transfusion therapy in adults ranged from 18.5 to 50.0 years. Forty-four patients underwent splenectomy; none received bone marrow transplantation. Complications related to TM and previous therapies included cholelithiasis, osteoporosis, kidney stones, HCV infection, pituitary gland hypofunction, hypothyroidism, hypoparathyroidism, chronic hepatopathy, cardiomyopathy, neurosensorial deafness, impaired glucose tolerance or type II diabetes, and slowed growth. The median total duration of chelation therapy was 35.2 years (first and third quartiles 29.0 and 36.7 years, respectively). The drug that was taken the longest was deferoxamine, at a maximum dose of $36.1 \pm 7.5 \mathrm{mg} / \mathrm{kg} / \mathrm{day}$.

\section{Cornea and Anterior Chamber}

Only four among adult patients (2.5\% of the sample) showed alterations in the front chamber, with bilateral ectropion uveae. Logistic regression returned no

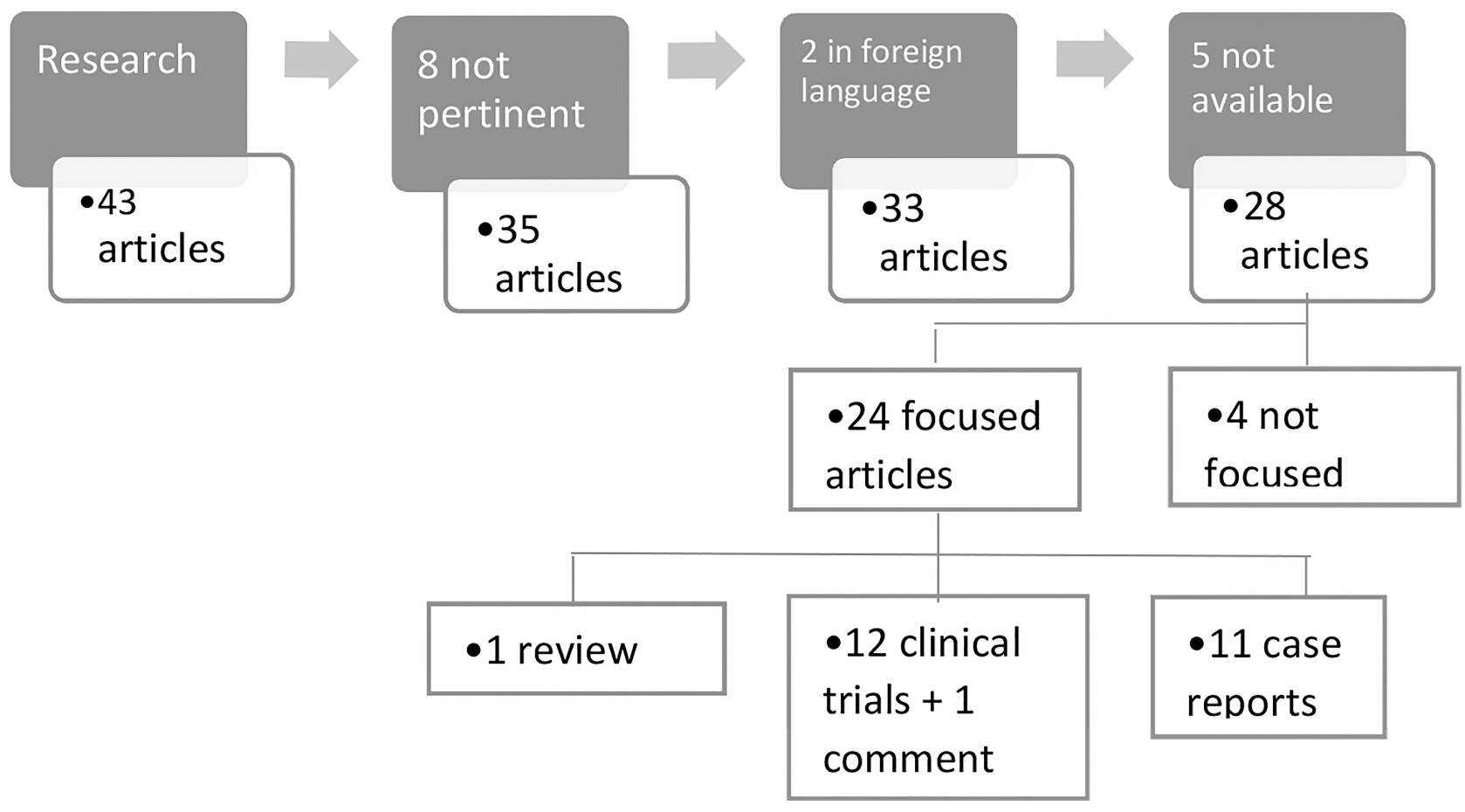

Figure I Process of bibliographical article selection. 

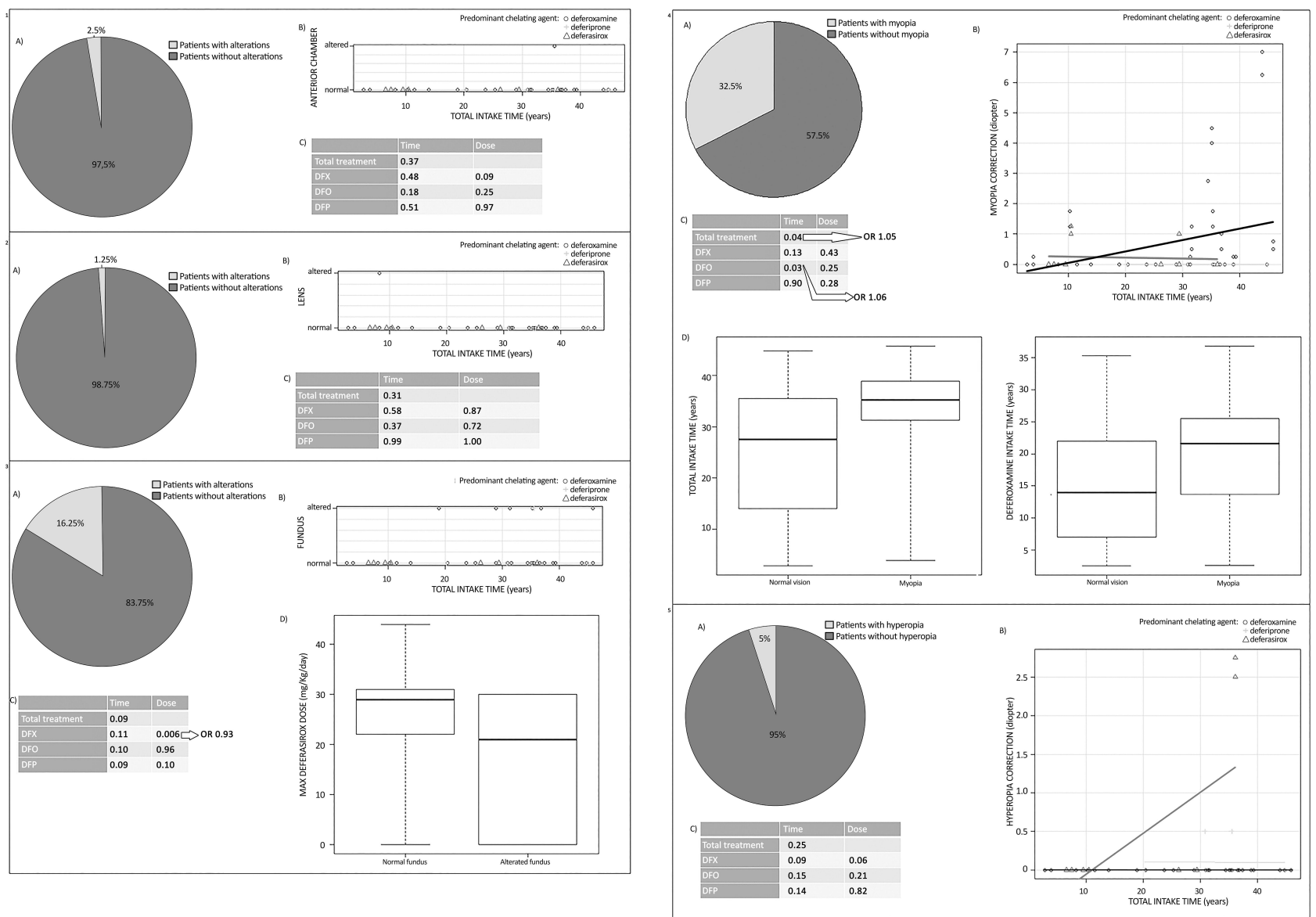

Figure 2 Statistical analysis of adverse reactions regarding affections of anterior chamber (I), lens (2), fundus oculi (3), myopia (4) and hyperopia (5) onset. Figure shows sample presentation (A), correlation analysis (B), logistic regression (C) and multivariate analysis (D).

Abbreviations: DFX, Deferasirox; DFO, Deferoxamina; DFP, Deferiprone.

significant $\mathrm{p}$-values for the correlation between alteration and treatment duration or doses (Figure 2.1).

Four articles reported the effects of iron chelating agents on the cornea and anterior chamber. None of the four clinical trials found statistically significant alterations, ${ }^{29,30,35,45}$ and a single article described alterations as being more frequent in the control group than in the chelated patients. ${ }^{45}$

\section{Lens}

Among the studied subjects, only two eyes $(1.25 \%$ of the sample) of a child, who had never taken deferiprone, had a mild sutural opacity. Logistic regression returned no significant $\mathrm{p}$-values for the correlation between this alteration with treatment duration and dosage (Figure 2.2).

Nine articles in the literature described lens anomalies during iron chelation therapy. However, five studies found no correlation between treatment and lens alterations ${ }^{41,45}$ or, the observed prevalence was not different from the one reported in the general population. ${ }^{30,31,42,43}$ Three case reports described four cases of lens opacities, three of which associated with deferiprone intake ${ }^{18,19}$ and one with high intravenous doses of deferoxamine. ${ }^{20}$

\section{Posterior Chamber and Fundus Oculi}

In our study sample, 26 eyes (16.25\% of the sample) of adult patients had non-serious and asymptomatic alterations of fundus oculi such as vascular irregularities, retinoschisis, pale optic nerve head and increased papillary excavation, retinal pigment epithelial alterations or chorioretinal atrophy. Logistic regression returned a statistically significant correlation only with deferasirox dosage (p-value 0.006 ; odds ratio [OR] 0.93 ), ie, a $7 \%$ protection factor for every $\mathrm{mg} / \mathrm{kg} / \mathrm{day}$. Multivariate analysis suggested that none of these elements was a modifier of drug's effects (Figure 2.3).

The literature search retrieved 22 articles describing fundus oculi alterations in patients treated with iron chelating agents: the only available review described, among the possible detectable alterations, a pseudoxanthoma-like (PXE) syndrome, tortuous vein vessels, degeneration of retinal pigment epithelium, retinal hemorrhages, retinal edema, pseudo- 
papillitis, macular scars, and a "salt and pepper" retinopathy. The study went on to suggest that the use of deferoxamine is often associated with macular and/or peripheral pigmentary degeneration ("bull's eye" maculopathy), while deferiprone does not seem to be related to retinal toxicity. ${ }^{32}$ Twelve studies found no difference between the patient group receiving last generation chelating agents at correct dose and healthy group, ${ }^{29,33,34,41}$ except for the average length of the fundus veins. ${ }^{46}$ More alterations were described in patients who took deferoxamine, especially at high doses and intravenously. ${ }^{16,30,35-39}$ Nine case reports described 10 cases of fundus alteration related to deferoxamine intake. ${ }^{20-28}$

\section{Visual Acuity}

None of the patients recruited in our study showed a significant reduction in BCVA from baseline.

The literature search retrieved 17 articles describing visual acuity in chelated patients: six out of eight studies found no statistically significant alterations ${ }^{31}$ and two described visual impairments related to deferoxamine intake. $^{36,40}$ Nine case reports described 10 patients taking deferoxamine, with visual impairment, sometimes associated with maculopathy, ${ }^{21-23}$ but more often with intravenous administration, and retinal pigment epithelium alterations that regressed after therapy discontinuation. ${ }^{20,24-28}$

\section{Refractive Errors and Presbyopia}

In our study sample, 52 eyes (32.5\% of the sample) had mostly mild myopic defects $(76.9 \%)$. Logistic regression returned a statistically significant correlation between myopia and chelation therapy (p-value 0.04; OR 1.05), ie, a $5 \%$ risk increase for each year of treatment. This defect appeared to be related to duration of deferoxamine therapy ( $p$-value 0.03; OR 1.06), ie, a 6\% per annum risk increase. Multivariate analysis showed that these results were not influenced by any other parameter (Figure 2.4). Eight eyes (5\% of the total) were affected by mild hyperopia. Logistic regression showed no correlation between this kind of defect and chelation therapy (Figure 2.5). Forty-six eyes (28.75\% of the sample) had mostly mild astigmatism (78.3\%); however, even in this case, the data found were not statistically significant (Figure 3.1).
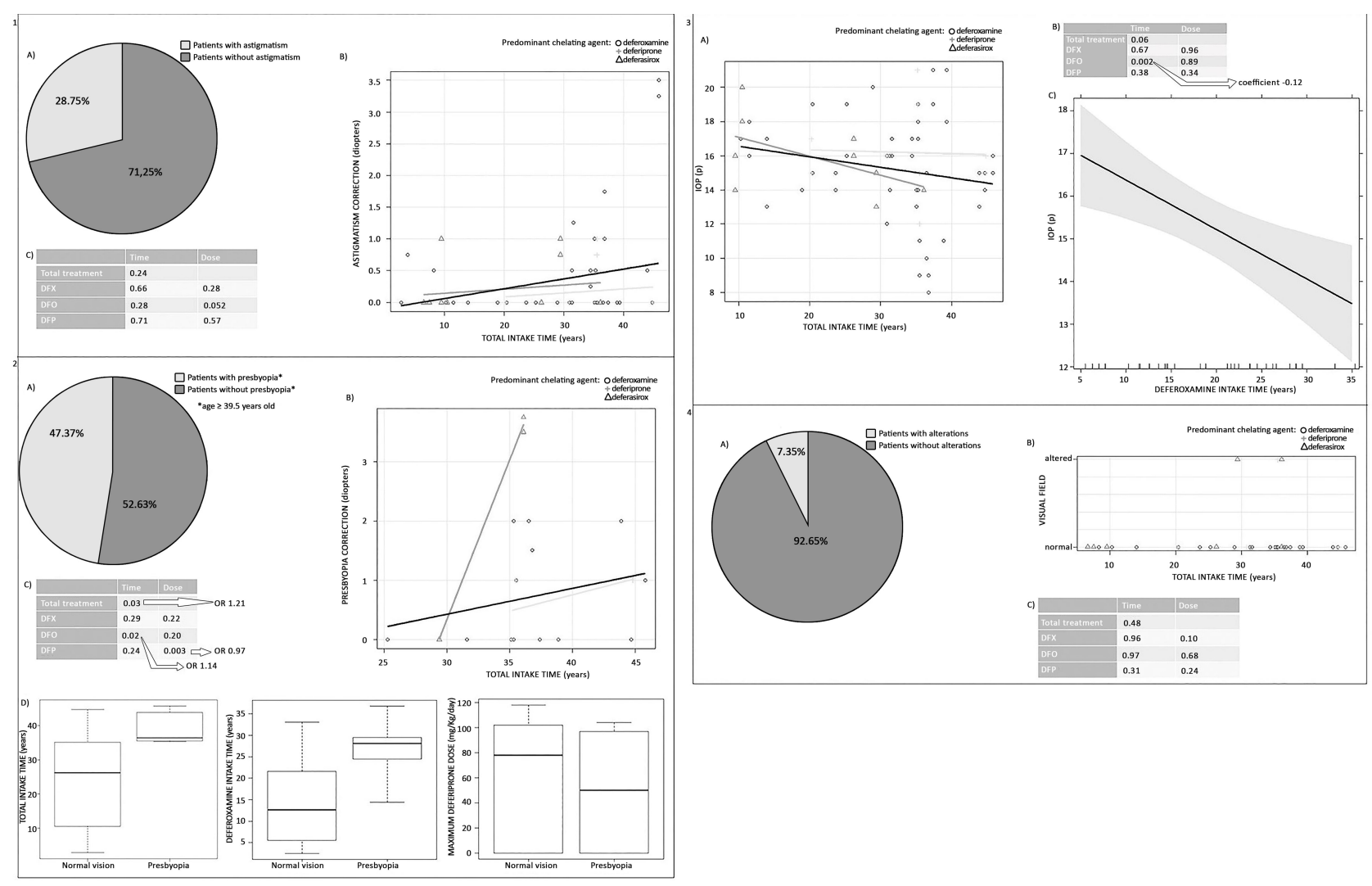

Figure 3 Statistical analysis of adverse reactions regarding astigmatism (I), presbyopia (2), IOP elevation (3), visual field alterations (4) onset. Figure shows sample presentation (A), correlation analysis (B), logistic regression (C) and multivariate analysis (D). Abbreviations: DFX, Deferasirox; DFO, Deferoxamina; DFP, Deferiprone. 
Instead, presbyopia affected 36 eyes $(22.5 \%$ of the sample). Since all the patients with this visual defect were older than 39.5 years, statistical analysis was only performed on these patients to assess whether therapy duration and doses might be related to the severity of visual defect. Results showed a significant correlation between presbyopia and total duration of therapy (p-value 0.03; OR 1.21 ), ie, a $21 \%$ risk increase for each year of treatment not influenced by patient age (p-value 0.98 ). Therefore, presbyopia appeared to be connected with the duration of deferoxamine therapy (p-value 0.02 ; OR 1.14 ), ie, a $14 \%$ increase in risk per year; Nevertheless, the association with deferiprone dose (p-value 0.003; OR 0.97) had a protective factor of $3 \%$ for each $\mathrm{mg} / \mathrm{kg} /$ day. Multivariate analysis revealed that none of these factors modified the parameters (Figure 3.2).

The literature search retrieved only one article ${ }^{41}$ that investigated the frequency of refractive errors and presbyopia but found that none of these defects were related to chelation therapy.

\section{Intraocular Pressure}

In our study, IOP was not measured in children less than 10 years of age (as collaboration of younger patients during the exam is difficult). The observed IOL was below or equal to $21 \mathrm{mmHg}$ in all other patients. Although IOP levels were within the normal range, linear regressions were performed to determine whether a correlation existed between higher IOP levels and chelation therapy intake: only the correlation with the duration of deferoxamine therapy was statistically significant (p-value 0.002 ; association coefficient -0.12 ), ie, a pressure reduction of $0.12 \mathrm{~mm} \mathrm{Hg}$ for each year of treatment (Figure 3.3).

The literature search retrieved two articles describing IOP in chelating patients: one study found no difference in IOP between patients treated with these drugs and healthy patients; ${ }^{30}$ similarly, a case report of a patient undergoing subcutaneous deferoxamine therapy specified that IOP was found to be in normal range. ${ }^{27}$

\section{Visual Field and Mean RNFL Thickness}

In our study sample, visual field was evaluated only in 72 patients (136 eyes), as collaboration by the younger children was insufficient for a reliable examination. Ten eyes ( $7.35 \%$ of the sample) exhibited visual field alterations: in two cases, a narrowing of the upper visual field was observed, even if not attributable to treatment, but related to blepharochalasis; in the other eight cases $(5.9 \%$ of the sample), a mild and asymptomatic incision in the temporal visual field was found. Logistic regression returned no significant correlation between visual field anomaly and treatment duration and doses (Figure 3.4).

None of the patients recruited in our study showed changes in the mean thickness of the RNFL, having all obtained values between $98.1 \pm 10.9 \mu \mathrm{m}$, a range of values taken as a reference for normality.

The literature search retrieved nine articles about visual field in patients receiving iron chelation therapy: a single review described a reduction in the visual field caused by deferoxamine. ${ }^{32}$ Of the four studies involving patients treated with deferoxamine, one study did not detect any abnormalities, ${ }^{29}$ while the others reported a narrowed visual field $\left(49^{\circ} \text { vs } 61^{\circ} \text { in the normal population }\right)^{33}$ and complete resolution of reduced central vision with treatment discontinuation ${ }^{36}$ and peripheral visual field defects resulting from intravenous administration. ${ }^{39}$ Four case reports described five cases of deferoxamine-related alterations such as central and paracentral scotomas ${ }^{20,23,25}$ or marked peripheral constraints and "tunnel vision" in some cases, ${ }^{20,26}$ mostly due to high doses and/or intravenous drug administration which improved after therapy discontinuation or dose reduction.

\section{Discussion}

The literature on ocular alterations in patients with betathalassemia is very poor. We were unable to determine whether the frequency in our sample is comparable to general population. Anterior chamber alterations, the only observed abnormality, were not statistically correlated with chelation therapy. Similarly, lens opacities were not associated with chelation therapy, although treatment-related cases have been described, probably related to either high dosage $\mathrm{e}^{20}$ or the particular pharmacokinetics of deferiprone. ${ }^{18,19,42}$ Deferiprone has been shown to induce iron shift from the intracellular compartment to the extracellular space, resulting in its deposition in the aqueous humour and activation of glutathione peroxidase, which leads to lens opacification. Cataract prevalence in the general population ranges from $0.23 \%$ in children ${ }^{47}$ to $70 \%$ in adults over 75 years of age, with an average between 15 and $19 \%{ }^{48}$ The percentage in our study sample falls within this range; however, the higher prevalence among the children may be due to the small sample size.

Our study shows that iron chelation therapy is not associated with fundus alterations; instead, a higher dose of deferasirox may even have a protective effect on the 
fundus oculi ( $7 \%$ per $\mathrm{mg} / \mathrm{kg} /$ day). The reasons for this possible protective effect are currently unknown. Therefore, this aspect needs to be investigated with further studies.

The literature reports that deferoxamine-related retinopathy probably has a multifactorial origin including electrolyte imbalance, with excessive metals removal (particularly copper and zinc) from the retina and possible iron-damaging effects on the blood-retinal barrier. ${ }^{20}$ Since it is more common in patients receiving higher dosage, especially via intravenous administration, it is recommended to maintain the deferoxamine therapeutic index below 0.025 and to perform periodic ophthalmological exams. ${ }^{24}$ In contrast, the increased length and tortuosity of venous vessels may be related to hematocrit reduction due to TM rather than chelation therapy. ${ }^{46}$ The prevalence of retinal anomalies is common in the general population; the most frequent form, however, is age-related macular degeneration in patients over 55 years old. ${ }^{49}$ Since our patients were 50 years old at most, we cannot say that their alterations were related to this condition. Accordingly, chelation therapy was excluded from among possible causes. Nonetheless, a recent study, ${ }^{50}$ published after completion of our study, reported that some betathalassemic patients receiving chelating therapy, without presenting any visible defects, showed electroretinogram alterations. A potential future area of focus for further study should consider this examination as a possible tool for identifying early alterations, even in asymptomatic patients.

None of our patients exhibited non-correctable alterations in visual acuity, demonstrating that chelating therapy (with subcutaneous deferoxamine or oral deferiprone or deferasirox at low doses calibrated to ferritin levels) is safe for retina and optic nerve function. The literature only describes the toxic effects of deferoxamine taken in excess when compared to the amount of available iron, as the unbound drug can accumulate in tissues, inhibiting DNA synthesis. On the contrary, a subcutaneous dose of $50 \mathrm{mg} /$ $\mathrm{kg}$ seems to be safe, ${ }^{36}$ whereas patients who, in acute situations, require intravenous administration (a rare eventuality in current times thanks to the availability of other chelating agents) should not exceed the maximum dose of $125 \mathrm{mg} / \mathrm{kg} /$ day. $^{20}$

Among the parameters evaluated, refractive errors were the most frequent ( $51 \%$ of the sample). While none of the three drugs had any influence on the development of hyperopia and astigmatism, the duration of iron chelation therapy could be a risk factor for the development of myopia (5\% per year of treatment). Deferoxamine in particular was proved to be a risk factor if continued for a long time (risk of $6 \%$ per annum). The prevalence of myopia in the Caucasian population is $33.1 \%$; likewise, the prevalence of hyperopia ranges from 3 to $57 \%$ and the one related to astigmatism is $46 \% .{ }^{51}$ In our sample, the prevalence of patients with refractive errors fell within the general population averages.

Our findings suggest that while total chelation therapy duration is not related to the severity of presbyopia, prolonged deferoxamine therapy increases the risk of early development by $14 \%$ per year. Conversely, a higher deferiprone dose, which ensures better ferritin control, could be considered as a protective factor $(3 \%$ protection factor per $\mathrm{mg} / \mathrm{kg} /$ day). The prevalence of presbyopia in our sample fell within the range for the general population. Presbyopia has its natural onset between age 40 and 50 years and the risk of developing it with advancing age is $100 \%$. ${ }^{52,53}$

For intraocular pressure, we found no abnormal IOP values. Though all were $\leq 21 \mathrm{mmHg}$, statistical analysis to assess the correlation between chelation and IOP values around the upper limits of normality suggested that prolonged therapy with these drugs is not related to ocular hypertension. On the contrary, continued use of deferoxamine could have a protective effect, with reduced IOP levels by $0.12 \mathrm{mmHg}$ per year of treatment. The fact that some patients reached the upper normality limit of 21 mmHg could be attributed to the measurement method: air tonometry tends to overestimate IOP as it induces a reflexive contraction of ocular and eyelid muscles.

Finally, statistical analysis of visual field alterations was very important in determining how low doses of subcutaneous deferoxamine or oral chelating agents did not cause significant disturbances, despite the lack of information regarding their distribution in the general population. In most published cases, abnormalities have been associated with the use of high-dose deferoxamine administered intravenously.

This study offers a hint for the enhancement of the drug database regarding the side effects in the ophthalmology field of these therapies.

A limitation of the present study is represented by the limited sample size. It is hoped that in the future this topic, on which little scientific evidence exists, can be thoroughly investigated with clinical trials with a greater number of patients. 
In conclusion, our study shows that modern chelation therapy is not associated with particular alterations in visual function: only myopia and premature presbyopia could be related to prolonged treatment with deferoxamine, while deferiprone, if taken at higher doses, plays a protective role against premature presbyopia. Based on our data, we can conclude that limiting deferoxamine treatment can help prevent ocular complications. In patients with TM, the use of deferiprone and/or deferasirox may be preferable and deferiprone, in particular, in patients over age 40 years. The prevalence of visual defects in our patients was lower than the mean rate in the general population: this suggests that correct management of therapy can play an important prevention role against the development of the majority of ocular alterations.

\section{Abbreviations}

DFO, Deferoxamina; DFP, Deferiprone; DFX, Deferasirox; RBC, Red Blood Cells; TM, Thalassemia Major; IOP, Intraocular Pressure; PXE, Pseudoxanthomalike Syndrome.

\section{Data Sharing Statement}

The data generated and analyzed during this study are stored in the repository of the Ophthalmology Unit of S. Luigi Gonzaga University Hospital but are available from the corresponding author on reasonable request.

\section{Ethics and Consent to Participate}

All procedures in this study concerning his conduction and documentation were performed in conformity with the ethical principles set out in the Helsinki Declaration and its revisions. This prospective cohort study was approved by the Ethics Committee of San Luigi Gonzaga University Hospital (University of Turin). Consent to participate was obtained in written form and has been registered for all subjects of this study. All participants were informed about the purpose of the study; a parent or legal guardian of the children provided informed consent.

\section{Acknowledgments}

This research was supported by University of Turin. We thank Dr. Lacroix, Cortassa, Corgiat Mecio, Ferrari, Chiambretto, and Lotti for the provided assistance during data collection and Dr. Gaglioti for assistance with patient enrollment.

\section{Funding}

This study was supported by the University of Turin. The above Institution had no role in the design of the study, in the collection, analysis, and interpretation of data and in writing the manuscript. No financial support/grant has been received by the authors for the realization of this study.

\section{Disclosure}

Prof. Dr. Antonio Giulio Piga reports grants from Novartis, grants from Apopharma, outside the submitted work. The authors declare that there are no conflicts of interest regarding the publication of this paper.

\section{References}

1. Galanello R, Origa R. Beta-thalassemia. Orphanet J Rare Dis. 2010;10.

2. Martin A, Thompson AA. Thalassemias. Pediatr Clin North Am. 2013;60(6):1383-1391. doi:10.1016/j.pcl.2013.08.008

3. Joly P, Pondarre C, Badens C. [Beta-thalassemias: molecular, epidemiological, diagnostical and clinical aspects]. Ann Biol Clin (Paris). 2014;72(6):639-668. Indonesian. doi:10.1684/abc.2014.1015.

4. Rachmilewitz EA, Giardina PJ. How I treat thalassemia. Blood. 2011;118(13):3479-3488. doi:10.1182/blood-2010-08-300335

5. Dubey AP, Parakh A, Dublish S. Current trends in the management of beta thalassemia. Indian J Pediatr. 2008;75(7):739-743. doi:10.1007/ s12098-008-0140-4

6. Angelucci E, Barosi G, Camaschella C, et al. Italian Society of Hematology practice guidelines for the management of iron overload in thalassemia major and related disorders. Haematologica. 2008;93 (5):741-752. doi:10.3324/haematol.12413

7. Langhi DJ, Ubiali EMA, Marques JFCJ, et al. Guidelines on Beta-thalassemia major - regular blood transfusion therapy: associacao brasileira de hematologia, hemoterapia e terapia celular: project guidelines: associacao Medica Brasileira - 2016. Rev Bras Hematol Hemoter. 2016;38(4):341-345. doi:10.1016/j.bjhh.2016.09.003

8. Prati D. Benefits and complications of regular blood transfusion in patients with beta-thalassaemia major. Vox Sang. 2000;79 (3):129-137. doi:10.1046/j.1423-0410.2000.7930129.x

9. Maggio A, Filosa A, Vitrano A, et al. Iron chelation therapy in thalassemia major: a systematic review with meta-analyses of 1520 patients included on randomized clinical trials. Blood Cells Mol Dis. 2011;47(3):166-175. doi:10.1016/j.bcmd.2011.07.002

10. Kontoghiorghe CN, Kontoghiorghes GJ. Efficacy and safety of iron-chelation therapy with deferoxamine, deferiprone, and deferasirox for the treatment of iron-loaded patients with nontransfusion-dependent thalassemia syndromes. Drug Des Devel Ther. 2016;10:465-481. doi:10.2147/DDDT.S79458

11. Xia S, Zhang W, Huang L, Jiang H. Comparative efficacy and safety of deferoxamine, deferiprone and deferasirox on severe thalassemia: a meta-analysis of 16 randomized controlled trials. PLoS One. 2013;8 (12):e82662. doi:10.1371/journal.pone.0082662

12. Hassan MAM, Tolba OA. Iron chelation monotherapy in transfusion-dependent beta-thalassemia major patients: a comparative study of deferasirox and deferoxamine. Electron Physician. 2016;8(5):2425-2431. doi:10.19082/2425

13. Borgna-Pignatti C, Marsella M. Iron Chelation in Thalassemia Major. Clin Ther. 2015;37(12):28662877. doi:10.1016/j.clinthera.2015.10. 001 
14. Saliba AN, Harb AR, Taher AT. Iron chelation therapy in transfusion-dependent thalassemia patients: current strategies and future directions. J Blood Med. 2015;6:197-209. doi:10.2147/JBM. S72463

15. Porter JB. Optimizing iron chelation strategies in beta-thalassaemia major. Blood Rev. 2009;23(Suppl 1):S3-7. doi:10.1016/S0268-960X (09)70003-7

16. Cohen AR, Galanello R, Piga A, Dipalma A, Vullo C, Tricta F. Safety profile of the oral iron chelator deferiprone: a multicentre study. $\mathrm{Br}$ J Haematol. 2000;108(2):305-312. doi:10.1046/j.1365-2141.2000. 01866.x

17. Al-Khabori M, Bhandari S, Al-Huneini M, Al-Farsi K, Panjwani V, Daar S. Side effects of Deferasirox Iron Chelation in patients with beta thalassemia major or intermedia. Oman Med J. 2013;28 (2):121124. doi:10.5001/omj.2013.31

18. Mehdizadeh M, Nowroozzadeh MH. Posterior subcapsular opacity in two patients with thalassaemia major following deferiprone consumption. Clin Exp Optom. 2009;92(4):392-394. doi:10.1111/ j.14440938.2009.00385.x

19. Parakh N, Sharma R, Prakash O, et al. Neurological complications and cataract in a child with thalassemia major treated with deferiprone. J Pediatr Hematol Oncol. 2015;37(7):e433-4. doi:10.1097/MPH.0000000000000391

20. Davies SC, Marcus RE, Hungerford JL, Miller MH, Arden GB, Huehns ER. Ocular toxicity of high-dose intravenous desferrioxamine. Lancet. 1983;2(8343):181-184. doi:10.1016/S014 0-6736(83)90170-8

21. Bansal V, Elgarbly I, Ghanchi FD, Atkinson PL. Bull's eye maculopathy with deferoxamine. Eur J Haematol. 2003;70(6):420-421. doi:10.1034/j.1600-0609.2003.00073.x

22. Gelman R, Kiss S, Tsang SH. Multimodal imaging in a case of deferoxamine-induced maculopathy. Retin Cases Brief Rep. 2014;8 (4):306-309. doi:10.1097/ICB.0000000000000059

23. Genead MA, Fishman GA, Anastasakis A, Lindeman M. Macular vitelliform lesion in desferrioxaminerelated retinopathy. Doc Ophthalmol. 2010;121(2):161-166. doi:10.1007/s10633-010-9236-z

24. Lai TYY, Lee GKY, Chan W-M, Lam DSC. Rapid development of severe toxic retinopathy associated with continuous intravenous deferoxamine infusion. Br J Ophthalmol. 2006;90(2):243-244. doi:10.1136/bjo.2005.080119

25. Lu M, Hansen RM, Cunningham MJ, Eklund SE, Fulton AB. Effects of desferoxamine on retinal and visual function. Arch Ophthalmol. 2007;125(11):1581-1582. doi:10.1001/archopht.125.11.1581

26. Simon S, Athanasiov PA, Jain R, Raymond G, Gilhotra JS. Desferrioxamine-related ocular toxicity: a case report. Indian J Ophthalmol. 2012;60(4):315-317. doi:10.4103/0301-4738.98714

27. Wu C-H, Yang C-P, Lai -C-C, Wu W-C, Chen Y-H. Deferoxamine retinopathy: spectral domain-optical coherence tomography findings. BMC Ophthalmol. 2014;14(1):88. doi:10.1186/1471-2415-14-88

28. Vahdani K, Makrygiannis G, Kaneshyogan H, Sian IS, Giasin O. Bilateral central serous retinopathy in a patient with paroxysmal nocturnal hemoglobinuria treated with deferoxamine. Eur J Ophthalmol. 2016;26(6):e152-e154. doi:10.5301/ejo.5000840

29. De Virgiliis S, Congia M, Turco MP, et al. Depletion of trace elements and acute ocular toxicity induced by desferrioxamine in patients with thalassaemia. Arch Dis Child. 1988;63(3):250-255. doi:10.1136/adc.63.3.250

30. El-Shazly AAE-F, Elkitkat RS, Ebeid WM, Deghedy MR. CORRELATION BETWEEN SUBFOVEAL CHOROIDAL THICKNESS AND FOVEAL THICKNESS IN THALASSEMIC PATIENTS. Retina. 2016;36(9):1767-1772. doi:10.1097/IAE.00000 00000000970

31. Triantafyllou N, Fisfis M, Sideris G, et al. Neurophysiological and neuro-otological study of homozygous beta-thalassemia under long-term desferrioxamine (DFO) treatment. Acta Neurol Scand. 1991;83(5):306-308. doi:10.1111/j.1600-0404.1991.tb04707.x
32. Bhoiwala DL, Dunaief JL. Retinal abnormalities in beta-thalassemia major. Surv Ophthalmol. 2016;61(1):33-50. doi:10.1016/j. survophthal.2015.08.005

33. Arden GB, Wonke B, Kennedy C, Huehns ER. Ocular changes in patients undergoing long-term desferrioxamine treatment. Br J Ophthalmol. 1984;68(12):873-877. doi:10.1136/bjo.68.12. 873

34. Chen S-H, Liang D-C, Lin H-C, Cheng S-Y, Chen L-J, Liu H-C. Auditory and visual toxicity during deferoxamine therapy in transfusion-dependent patients. J Pediatr Hematol Oncol. 2005;27 (12):651653. doi:10.1097/01.mph.0000194019.95096.b6

35. Gartaganis SP, Zoumbos N, Koliopoulos JX, Mela EK. Contrast sensitivity function in patients with beta-thalassemia major. Acta Ophthalmol Scand. 2000;78(5):512-515. doi:10.1034/j.16000420.2000.078005512.x

36. Olivieri NF, Buncic JR, Chew E, et al. Visual and auditory neurotoxicity in patients receiving subcutaneous deferoxamine infusions. $N$ Engl J Med. 1986;314(14):869-873. doi:10.1056/NEJM1986 04033141402

37. Viola F, Barteselli G, Dell'Arti L, et al. Multimodal imaging in deferoxamine retinopathy. Retina. 2014;34(7):1428-1438. doi:10.1097/IAE.0000000000000073

38. Viola F, Barteselli G, Dell'arti L, et al. Abnormal fundus autofluorescence results of patients in longterm treatment with deferoxamine. Ophthalmology. 2012;119(8):1693-1700. doi:10.1016/j.ophtha.20 12.01.039

39. Wong V, Li A, Lee AC. Neurophysiologic study of beta-thalassemia patients. J Child Neurol. 1993;8(4):330-335. doi:10.1177/0883 07389300800407

40. Cohen A, Martin M, Mizanin J, Konkle DF, Schwartz E. Vision and hearing during deferoxamine therapy. J Pediatr. 1990;117(2 Pt 1):326-330. doi:10.1016/S0022-3476(05)80556-6

41. Merchant RH, Punde H, Thacker N, Bhatt D. Ophthalmic Evaluation in Beta-Thalassemia. Indian $J$ Pediatr. 2017;84(7):509-514. doi:10.1007/s12098-017-2339-8

42. Masera N, Rescaldani C, Azzolini M, et al. Development of lens opacities with peculiar characteristics in patients affected by thalassemia major on chelating treatment with deferasirox (ICL670) at the pediatric clinic in Monza, Italy. Haematologica. 2008;93(1):e9-10. doi:10.3324/haematol.11782

43. Ford JM, Rojkjaer L. Comment to: development of lens opacities with peculiar characteristics in patients affected by thalassemia major on chelating treatment with deferasirox. Haematologica. 2008;93(6): e9-10. doi:10.3324/haematol.12944

44. Piga A, Longo F, Musallam KM, et al. Assessment and management of iron overload in beta thalassemia major patients during the 21st century: a real-life experience from the Italian WEBTHAL project. $\mathrm{Br} J$ Haematol. 2013;161(6):872-883. doi:10.1111/bjh. 12340

45. Jethani J, Marwah K, Patel S, Shah B. Ocular abnormalities in patients with beta thalassemia on transfusion and chelation therapy: our experience. Indian $J$ Ophthalmol. 2010;58(5):451-452. doi:10.4103/0301-4738.67061

46. Incorvaia C, Parmeggiani F, Costagliola C, Perri P, D’Angelo S, Sebastiani A. Quantitative evaluation of the retinal venous tortuosity in chronic anaemic patients affected by beta-thalassaemia major. Eye (Lond). 2003;17(3):324-329. doi:10.1038/sj.eye.67 00352

47. Sheeladevi S, Lawrenson JG, Fielder AR, Suttle CM. Global prevalence of childhood cataract: a systematic review. Eye (Lond). 2016;30 (9):1160-1169. doi:10.1038/eye.2016.156

48. Acosta R, Hoffmeister L, Roman R, Comas M, Castilla M, Castells X. [Systematic review of population based studies of the prevalence of cataracts]. Arch Soc Esp Oftalmol. 2006;81 (9):509-516. Indonesian. doi:10.4321/s0365-66912006000900 005 . 
49. Zarbin MA, Casaroli-Marano RP, Rosenfeld PJ. Age-related macular degeneration: clinical findings, histopathology and imaging techniques. Dev Ophthalmol. 2014;53:1-32. doi:10.1159/000358536

50. Dettoraki M, Kattamis A, Ladas I, et al. Electrophysiological assessment for early detection of retinal dysfunction in beta-thalassemia major patients. Graefes Arch Clin Exp Ophthalmol. 2017;255 (7):1349-1358. doi:10.1007/s00417-017-3650-9

51. Wu P-C, Huang H-M, Yu H-J, Fang P-C, Chen C-T. Epidemiology of Myopia. Asia Pac J Ophthalmol (Phila). 2016;5(6):386-393. doi:10.1097/APO.0000000000000236
52. Nuzzi R, Schiavino R. Geriatric ophthalmology. Panminerva Med. 1993;35(1):36-46. PMID: 8316402.

53. Weale RA. Epidemiology of refractive errors and presbyopia. Surv Ophthalmol. 2003;48(5):515-543. doi:10.1016/S0039-6257(03) 00086-9

\section{Publish your work in this journal}

Clinical Ophthalmology is an international, peer-reviewed journal covering all subspecialties within ophthalmology. Key topics include: Optometry; Visual science; Pharmacology and drug therapy in eye diseases; Basic Sciences; Primary and Secondary eye care; Patient Safety and Quality of Care Improvements. This journal is indexed on PubMed

Submit your manuscript here: https://www.dovepress.com/clinical-ophthalmology-journal
Central and CAS, and is the official journal of The Society of Clinical Ophthalmology (SCO). The manuscript management system is completely online and includes a very quick and fair peer-review system, which is all easy to use. Visit http://www.dovepress.com/ testimonials.php to read real quotes from published authors. 